\section{Gender effects in medical education: implications for training and gender equity in regional anesthesia}

\author{
Navdeep S Sidhu, ${ }^{1}$ Nina Civil ${ }^{2}$
}

\section{INTRODUCTION}

Activist Marian Wright Edelman says, 'You can't be what you can't see'. A lack of suitable role models contributes to the paucity of women in clinical and academic leadership positions. Gender imbalance is seen in invited keynote speakers at specialty conferences, ${ }^{1}{ }^{2}$ within leadership groups, ${ }^{3-5}$ on international panels ${ }^{6}$ and peak specialty honor awards. ${ }^{78}$ The Women in Anesthesiology group was formed in 2015 to address the relative lack of professional respect in comparison with male peers, the gender-based pay gap, unfair professional leave rules and policies, and the absence of mentorship and consequent lack of women in leadership roles. ${ }^{9}$

While recent publications discuss the issue of gender bias and lack of women leaders in anesthesiology ${ }^{9} 10$ and pain medicine, ${ }^{11}$ there is no published literature on specific gender effects in anesthesiology education. We hypothesize that gender effects exist in anesthesiology residency education, contributing to gender inequity. In this article, we outline recent evidence on gender effects in medical education. The confidence gap and unconscious bias are described in relation to this. We offer a conceptual model on how this may influence gender equity in a procedural-based specialty such as regional anesthesia. Lastly, we pose some questions that we believe warrant further investigation.

\section{DISCUSSION}

\section{The confidence gap}

Despite the gender bias that women face in their clinical practice, they perform at least as well as men and, in some studies, better than men. Male and female residents perform equally well in standardized laparoscopy simulation assessments. ${ }^{12}$

${ }^{1}$ Department of Anaesthesia and Perioperative Medicine, North Shore Hospital, Auckland, New Zealand ${ }^{2}$ Department of Anaesthesia and Pain Medicine, Waikato Hospital, Hamilton, New Zealand

Correspondence to Dr Navdeep S Sidhu, Department of Anaesthesia and Perioperative Medicine, North Shore Hospital, Auckland 0622, New Zealand; nav.sidhu@waitematadhb.govt.nz
When novices are taught basic surgical skills and subsequently assessed on their performance, women outperform men in some skills, while others show no difference. ${ }^{13}$ A large Canadian population-based cohort study of 104630 patients treated by over 3000 surgeons showed that patients treated by female surgeons were less likely to die, had less hospital readmissions and less complications at 30 days (female $11.1 \%$ vs male $11.6 \% ; p=0.02$ ). ${ }^{14}$ An analysis of over 1.5 million hospital admissions showed that patients treated by female internists had lower 30-day mortality $(11.1 \%$ vs $11.5 \%, \mathrm{p}<0.001$, number needed to treat to prevent one death $=233$ ) and lower 30-day readmissions $(15.0 \%$ vs $15.6 \%, \mathrm{p}<0.001$, number needed to treat to prevent one readmission $=182$ ) than patients cared for by male internists, adjusted for patient confounders, physician characteristics and hospital fixed effects. ${ }^{15}$ The latter two studies indicate that intrinsic differences in practice patterns between men and women may have implications on patient outcome.

In juxtaposition to the evidence supporting the skills of female clinicians, there is evidence that women display less confidence in their abilities relative to their male colleagues. Consider the following scenario: two residents, male and female, both with identical prior teaching and experience with a particular nerve block. The supervising clinician believes them to be equally competent and asks them to perform the block on the next patient. If the resident is male, he responds, 'Okay, I've done 3 of these blocks already'. If the resident is female, she responds, 'Okay, but I've only done 3 of these blocks before'. The female resident highlights her previous experience as if it illustrates a shortcoming, while the male resident highlights his identical previous experience as if it proves his competence. This divergence in behavior is termed the confidence gap. In this example, the two residents are not overconfident or underconfident; both function within the bounds of acceptable confidence, but a gap is still observed. Potential consequences of different confidence levels are outlined in table 1 , with both very high and low levels of confidence having negative consequences. Individual women and men display a range of behaviors and levels of confidence, and this might be dependent on the situation, environment, and domain knowledge, as well as underlying individual personality traits. Confidence levels are usually self-reported and difficult to measure empirically. In the scenario above, many of us might react to the woman's statement by being a little more vigilant in our observations of her or perhaps deny her the clinical autonomy afforded to an equally experienced peer. We postulate that this unconscious bias towards the confidence gap contributes to the inequitable treatment of female trainees.

The confidence gap has been well described in the social sciences. Between elementary and high school, girls' self-esteem drops significantly, more so than boys'. ${ }^{16}$ Women will apply for promotions only when they meet all of the described qualifications, while men will apply even when they meet just over half. ${ }^{17} 18$ Men initiate negotiations to increase their salary more often than women, and when women do ask, they ask for a less substantial raise. ${ }^{19}$ The 'imposter syndrome' describes this issue with professional confidence: feelings of self-doubt and a concern that one is an 'imposter' who could be discovered at any time. ${ }^{18}$ Negative labels are frequently applied to women who display higher levels of confidence. $^{20}$ Gender norms for many

Table 1 Potential consequences of different confidence levels

\begin{tabular}{ll}
\hline Confidence level & Potential consequences \\
\hline Overconfident & $\begin{array}{l}\text { Commonly misinterpreted by others as marker for adequate competence. } \\
\text { Individual not aware of limits of competence. }\end{array}$ \\
Takes more risks with procedures or clinical decisions.
\end{tabular}


societies have women in supportive and nurturing roles, while men are regarded as decision makers and providers. Both men and women pay a social price if they stray from gender norms, ${ }^{21}$ embedding these learnt behaviors.

There is emerging evidence of the confidence gap in graduate medical education. A survey of 4136 general surgery residents showed that more men than women felt their operating skill level was appropriate (men $75 \%$ vs women $70 \%$; $<0.001$ ), and more women were concerned about not feeling confident enough to perform procedures independently by the end of training (men $22 \%$ vs women $37 \%$; $\mathrm{p}<0.001) .{ }^{22}$ When residents were asked to predict their performance score on a standardized laparoscopy simulator, women predicted significantly lower scores for themselves even after controlling for factors such as level of training, despite no difference in actual performance. ${ }^{12}$ Stephens et $a l^{23}$ surveyed cardiothoracic residents and showed that women were less likely to feel prepared technically (men 90\% vs women 77\%; p=0.01) and less confident about practicing independently (men $87 \%$ vs women $71 \%$; $\mathrm{p}=0.01)$. Myers et $a l^{24}$ surveyed general surgery residents showing that female residents were less likely to self-identify as a 'surgeon' (women 11\% vs men 38\%; $\mathrm{p}<0.001)$.

A similar pattern is observed outside of the surgical sphere and in different cultures. A survey of 1124 second-year residents in Japan showed female residents displaying less confidence in three of the four surveyed competencies, one of which was procedural skills. ${ }^{25}$ Male doctors in the UK were 1.39 times more confident than their female counterparts at performing a range of procedures, independent of level of training or previous experience with that procedure. ${ }^{26}$ Female medical students at the end of their first year of study in the UK state significantly lower confidence levels for a range of transferable skills compared with their male counterparts. ${ }^{27}$ An online mobile web platform compared the relationship between confidence and accuracy in male and female medical students, analyzing multiple-choice question responses from 1021 learners who had answered over 50 questions each. ${ }^{28}$ Before providing the answer for each question, learners were required to rate their level of confidence as 'I'm sure', 'feeling lucky' or 'no clue'. A higher proportion of male learners were confident ('I'm sure') of their answers (female $39.5 \%$ vs male $44.4 \%$; $=0.001$ ), but more women in that group provided accurate answers (female $80.5 \%$ vs male $78.3 \%, \mathrm{p}=0.002) .{ }^{28}$ Not only do women frequently state being less confident, they are often perceived as such. In a standardized patient interaction examination, female medical students in a US medical school appeared significantly less confident than male counterparts to external observers. $^{29}$

It appears women are disadvantaged even when they display more confident behaviors. Dayal et $a l^{30}$ compared more than 33000 milestone evaluations from 359 emergency medicine residents in eight institutions, showing that male residents had a higher rate of milestone attainment throughout training despite men and women starting at similar levels in PGY1. This occurred over all 23 competencies, with the largest difference seen in 'procedural skills' and 'airway'. The authors put forward several possible explanations for their finding, including that PGY3 residents have assertiveness and a commanding presence in ways that are characteristically male and that are regarded as undesirable when exhibited by a woman. Mueller et al qualitatively analyzed 1317 direct observation evaluations over 3 years in an emergency medicine residency program, revealing that stereotypically masculine traits were viewed by assessors as a requirement for residents to excel. ${ }^{31}$ However, when female residents displayed a masculine trait such as autonomous leadership, they received mixed messages, praised by some attendings but criticized by others for being argumentative. ${ }^{31}$ Ninety-two percent of female residents received negative personality comments, compared with $50 \%$ of male residents. ${ }^{31}$ Similarly, Myers et al showed that female general surgical residents displaying confident behavior were more likely to receive criticism from attendings (female $56 \%$ vs male 29\%, $\mathrm{p}<0.001){ }^{24}$ Women assuming stereotypical male attributes, such as those typically required to lead a resuscitation event, have

also felt the need to apologize for straying from their gender role. ${ }^{32}$

To our knowledge, there are no studies investigating the gender confidence gap in regional anesthesia. We conducted a small intradepartmental survey to investigate the possibility of a gender confidence gap. One author assessed the anesthesiologists in their department, categorizing them as either 'regional anesthetists' (the local designation for physician anesthesiologists with expertise in performing peripheral nerve blocks) or 'not', using objective measures based on knowledge of faculty clinical practice, previous fellowships, and clinical interactions. Faculty were contacted via email to ask if they perceived themselves to be 'regional anesthetists,' providing only 'yes' or 'no' answers with a 100\% response rate after some additional contact via text messaging. No further definition or detail was given, as there is no consensus on defining expertise or competence in regional anesthesia. The results of this small survey were striking. There was concordance between the self-reported categorization of the female anesthesiologists and the objective categorization. However, 50\% more male anesthesiologists perceived themselves to be 'regional anesthetists' than had been objectively assessed as such. This gender difference persisted, even when groups were categorized by seniority based on number of years as an attending (see table 2). We acknowledge that this was not a scientific study, but the exercise demonstrated to us that gender effects in regional anesthesia are plausible, and in this small survey, suggested a confidence gap driven by relative overconfidence of the male anesthesiologists, rather than low confidence of the female anesthesiologists. This interpretation of the findings presumes that being labeled a 'regional anesthetist' is not undesirable and that both groups value the distinction equally.

Table 2 Gender differences between objective assessment and self-perceived status as 'regional anesthetists' in a teaching hospital

\begin{tabular}{llllll}
\hline & \multicolumn{2}{l}{ Men, $\mathbf{n}(\%)$} & & Women, $\mathbf{n}(\%)$ & \\
\cline { 2 - 3 } \cline { 5 - 6 } & $\begin{array}{l}\text { Objective } \\
\text { assessment }\end{array}$ & $\begin{array}{l}\text { Self- } \\
\text { perception* }\end{array}$ & & $\begin{array}{l}\text { Objective } \\
\text { assessment }\end{array}$ & $\begin{array}{l}\text { Self- } \\
\text { perceptiont }\end{array}$ \\
\hline Total & $15 / 37(41)$ & $23 / 37(62)$ & & $8 / 21(38)$ & $8 / 21(38)$ \\
$>10$ years as attending & $10 / 25(40)$ & $15 / 25(60)$ & & $5 / 12(42)$ & $5 / 12(42)$ \\
$<10$ years as attending & $5 / 12(42)$ & $8 / 12(67)$ & & $3 / 9(33)$ & $3 / 9(33)$ \\
\hline
\end{tabular}

*All male attendings who were assessed as a 'regional anesthetist' perceived themselves as such, plus a further eight men.

tOne female attending who was assessed as a 'regional anesthetist' perceived herself otherwise, and vice versa, thus resulting in no overall change. 


\section{Unconscious bias}

Unconscious (or implicit) bias refers to how we unknowingly draw on assumptions about individuals or groups in order to make decisions about them. ${ }^{33}$ These judgements are involuntary and automatic and occur beyond our awareness (in psychology, the subconscious mind refers to that part of consciousness that we are not actively aware of but can be recalled, whereas the unconscious mind consists of processes that are automatic and not available to introspection). As a species, we have developed this ability because it helps us become more efficient when judging a person or a situation. It is a byproduct of sociocultural learning and experiences, reflecting preferences for one's own group or the dominant group in society. ${ }^{33}$ There are validated tests available to help identify one's own unconscious biases, such as Harvard University's Implicit Association Test. ${ }^{34}$ Harmful consequences may result when decisions are made based on assumptions or stereotypes, and unconscious bias is recognized as a cause of unintentional gender discrimination in the workplace. ${ }^{9}$

There are many examples of unconscious bias against women in medicine. Physicians (attendings and other residents) are more likely to disregard the credentials of female residents when introducing the resident to a patient (female $56 \%$ vs male $8 \% ; \mathrm{p}<0.001)$, while patients display a similar but more profound disregard of female residents' credentials (female 79\% vs male $12 \% ; \mathrm{p}<0.001) .{ }^{24}$ Similarly, an analysis of 321 grand round introductions identified that when a man introduced a speaker, they included the professional title $72.4 \%$ of the time for male speakers versus $49.2 \%$ for female speakers. ${ }^{35}$ In comparison, women included the professional title for $95.0 \%$ of male speakers and $97.8 \%$ of female speakers. ${ }^{35}$ These actions illustrate, and reinforce, an unconscious bias against women in professional practice.

There are no direct means to measure unconscious bias in medical education, but strong inferences can be made from some studies. Meyerson et al sought to measure the effect of gender on surgical resident autonomy in the operating room. ${ }^{36}$ Levels of autonomy were documented by 33 residents and 48 faculty during 596 teaching encounters in seven residency programs. Meaningful autonomy was defined as 'passive help' or 'supervision only' for 'key portions of the procedure'. The study found that significantly less meaningful autonomy was afforded to female residents, as assessed by faculty (\% of teaching encounters; female $30 \%$ vs male $37 \%$; $\mathrm{p}=0.02)$ and as perceived by residents (female $19 \%$ vs male $33 \%$; $<<0.001$ ). $^{36}$ This was despite a higher proportion of teaching encounters with female residents involving senior residents (female $71 \%$ vs male $51 \% ; \mathrm{p}<0.001$ ) and no difference in case difficulty between genders. Interestingly, equal levels of autonomy were given by female faculty but male faculty assessed themselves as giving more autonomy to male residents (female $23 \%$ vs male $36 \%$ ). No male attending afforded any female resident the highest level of meaningful autonomy ('supervision only'). ${ }^{36}$ Despite there being no objective reasons to do so, female residents were denied appropriate autonomy in the operating theater. Nebeker et al investigated gender differences in 727 learning objectives generated by 125 residents in consultation with attending surgeons, each learning objective generated prior to a case and classified as either knowledge-based, skill-based, or attitude-based. ${ }^{37}$ The use of learning objectives for each teaching encounter is recognized as good educational practice and is a feature of many deliberate teaching tools. ${ }^{38}$ They found that female residents were 1.4 times more likely to select a knowledge-based learning objective over a skill-based one, and when the attending surgeon was female, all residents were more likely to select knowledge (1.6 times) and attitude ( 2.1 times) over skill. ${ }^{37}$ This suggests that the women valued and were valued for their knowledge, but less so for their procedural skills.

\section{Conceptual model}

Figure 1 describes a conceptual model for the interaction between bias, confidence and learning. The confidence gap and unconscious bias combine to result in decreased levels of autonomy for affected groups of residents, which limits access to hands-on practice, impairs the learning experience and reinforces the confidence gap. This conceptual model does not aim to explain all the complex causes and effects of gender inequity but attempts to illustrate some of what we know from the medical literature.

\section{Implications for regional anesthesia}

Regional anesthesia is a highly procedural-based subspecialty, and it is possible that the gender effects observed in surgical specialties are present in regional anesthesia. The Accreditation Council for Graduate Medical Education data on gender preferences for regional anesthesia training is incomplete, as only $9 / 67$ programs were initially accredited. ${ }^{39}$ In Canada, female anesthesiology residents are less likely to pursue a subspecialty fellowship compared with male peers. ${ }^{40}$ If there is an advantage to patients in having female clinicians involved in their care, ${ }^{14} 15$ then increased representation of women in regional anesthesia is highly desirable.

In our opinion, the regional anesthesia community of practice should investigate the extent of gender effects in our subspecialty. Does is exist? How prevalent is it? Is there a confidence gap between male and female residents in regional anesthesia? Are we biased against women with regards to teaching, levels of supervision, or procedural responsibility? Does our unconscious bias cause us to label women as underconfident when they exhibit lower confidence levels than men, despite their confidence levels being completely acceptable and within the range required for safe practice? Do patients or supervisors misinterpret lower confidence, even when acceptable and safe, as a deficit in competence? Do gender effects in training negatively affect subspecialty fellowship interest or selection? Do these have subsequent effects on female representation in

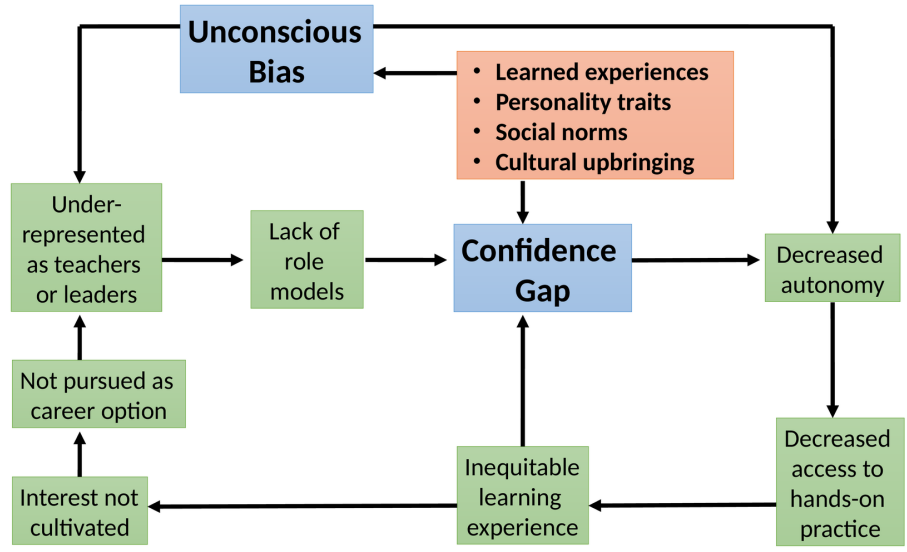

Figure 1 Conceptual model for the interaction between bias, confidence and learning. 
visible leadership roles? Based on evidence from other specialties, these are questions that warrant further investigation.

\section{CONCLUSIONS}

It is our opinion that educators and researchers in regional anesthesia are obliged to investigate for gender effects in regional anesthesia training. The evidence from other specialties suggests inequitable treatment when female trainees display relatively less confidence in their abilities (incorrectly perceived as decreased competence) and also when they display confidence levels similar to their male counterparts (perceived as overconfidence or arrogance, due to being stereotypically 'unfemale' behavior). When discussing the confidence gap, it is not uncommon to hear calls for 'closing the gap' implying that women should strive to display levels of confidence similar to men. This narrative needs to change. Part of the issue is that we tend to use male confidence levels as the reference point when there is no evidence to suggest that this should be the case. We need to accept that 'less confident' does not mean 'underconfident' and that the problem is our unconscious bias, not the confidence gap per se. Unconscious bias can be mitigated by a commitment to manage it at a personal and institutional level, through a combination of awareness, instilling concern about the consequences of that bias and application of specific strategies to reduce bias. ${ }^{41} 42$

Though this article discusses gender, unconscious bias is displayed in relation to race, skin tone, weight, age, nationality, language/accent, sexuality, appearance, religion (or lack thereof), education status, disability and so on. It is normal for these biases to be present, even though they may contradict our own explicit values and commitment to equity. The intersectionality phenomenon may mean that the effects of unconscious bias are amplified in women who belong to other marginalized groups. Efforts to rectify known gender imbalance at higher levels of our specialty should begin by ensuring that trainees are treated fairly and equitably, enabling a diverse skilled workforce to provide best patient care to our diverse populations.

\section{Twitter@NavSidhu08@CivilNina}

Contributors Both authors contributed equally to the research and writing of this manuscript.

Funding The authors have not declared a specific grant for this research from any funding agency in the public, commercial or not-for-profit sectors.

Competing interests None declared.

Patient consent for publication Not required.
Provenance and peer review Not commissioned; externally peer reviewed.

(C) American Society of Regional Anesthesia \& Pain Medicine 2019. No commercial re-use. See rights and permissions. Published by BMJ.

Some references from this article were presented at the 2018 Australian and New Zealand College of Anaesthetists (ANZCA) Annual Scientific Meeting in Sydney, Australia, 7-11 May 2018.

\section{Check for updates}

To cite Sidhu NS, Civil N. Reg Anesth Pain Med 2019;44:494-498.

Received 5 September 2018

Revised 12 October 2018

Accepted 19 November 2018

Published Online First 11 January 2019

Reg Anesth Pain Med 2019;44:494-498.

doi:10.1136/rapm-2018-100080

\section{REFERENCES}

1 Mehta S, Rose L, Cook D, et al. The SPEAKER gender gap at critical care conferences. Crit Care Med 2018:46:991-6.

2 Modra LJ, Austin DE, Yong SA, et al. Female representation at Australasian specialty conferences. Med J Aust 2016;204:385.

3 Leslie K, Hopf HW, Houston P, et al. Women, minorities, and leadership in anesthesiology: take the Pledge. Anesth Analg 2017:124:1394-6.

4 Toledo P, Duce L, Adams J, et al. Diversity in the American Society of Anesthesiologists leadership. Anesth Analg 2017;124:1611-6.

5 Fahy BG, Culley DJ, Sun $\mathrm{H}$, et al. Gender distribution of the American Board of anesthesiology Diplomates, examiners, and directors (1985-2015). Anesth Analg 2018:127:564-8.

6 Penny M, Jeffries R, Grant J, et al. Women and academic medicine: a review of the evidence on female representation. J R Soc Med 2014;107:259-63.

7 Mottiar M. Because it's 2018: women in Canadian anesthesiology. Can J Anesth/J Can Anesth 2018;65:953-4.

8 Bruguera M, Arrizabalaga P, Londoño MC, et al. Professional recognition of female and male doctors. Rev Clin Esp 2014;214:69-73.

9 Chandrabose RK, Pearson ACS. Organizing women in anesthesiology. Int Anesthesiol Clin 2018;56:21-43.

10 Shillcutt S, Peterson-Layne C. More than the money: work culture challenges for women anesthesiologists. Int Anesthesiol Clin 2018;56:44-58.

11 Doshi TL, Bicket MC. Why aren't there more female pain medicine physicians? Reg Anesth Pain Med 2018:43:516-20

12 Flyckt RL, White EE, Goodman LR, et al. The use of laparoscopy simulation to explore gender differences in resident surgical confidence. Obstet Gynecol Int 2017:2017:1-7.

13 Lou Z, Yan FH, Zhao ZQ, et al. The sex difference in basic surgical skills learning: a comparative study. $J$ Surg Educ 2016;73:902-5.

14 Wallis CJ, Ravi B, Coburn N, et al. Comparison of postoperative outcomes among patients treated by male and female surgeons: a population based matched cohort study. BMJ 2017;359:44366.

15 Tsugawa Y, Jena AB, Figueroa JF, et al. Comparison of hospital mortality and readmission rates for Medicare patients treated by male vs female physicians. JAMA Intern Med 2017;177:206-13.

16 Greenberg-Lake: The Analysis Group. Shortchanging girls, shortchanging America: American Association of university women. 1994. Available: https://www.aauw. org/files/2013/02/shortchanging-girls-shortchanging- america-executive-summary.pdf [Accessed 10 Oct 2018].

17 Shipman C, Kay K. The confidence gap: The Atlantic. 2014. Available: https://www.theatlantic.com/ magazine/archive/2014/05/the-confidence-gap/ 359815/ [Accessed 19 May 2018].

18 Zenger J. The confidence gap in men and women: why it matters and how to overcome it: Forbes Magazine. 2018. Available: https://www.forbes.com/sites/ jackzenger/2018/04/08/the-confidence-gap-in-menand-women-why-it-matters-and-how-to-overcome-it/ [Accessed 6 Jun 2018].

19 Babcock L, Laschever S. Women don't ask. Negotiation and the gender divide. Princeton, NJ: Princeton University Press, 2003.

20 Humphrey J. The End Of "Bitchy": Addressing stereotypes of women at work. Fast company magazine. 2015. Available: https://www.fastcompany. com/3041942/the-end-of-bitchy-addressingstereotypes-of-women-at-work [Accessed 6 Jun 2018].

21 Valian V. Evaluating women and men. Why so slow?: The advancement of women. Cambridge, MA: MIT Press, 1999.

22 Bucholz EM, Sue GR, Yeo H, et al. Our trainees' confidence: results from a national survey of 4136 us general Surgery residents. Arch Surg 2011;146:907-14.

23 Stephens EH, Robich MP, Walters DM, et al. Gender and cardiothoracic surgery training: specialty interests, satisfaction, and career pathways. Ann Thorac Surg 2016;102:200-6

24 Myers SP, Hill KA, Nicholson KJ, et al. A qualitative study of gender differences in the experiences of general surgery trainees. J Surg Res 2018;228:127-34.

25 Nomura K, Yano E, Fukui T. Gender differences in clinical confidence: a nationwide survey of resident physicians in Japan. Acad Med 2010;85:647-53.

26 Connick RM, Connick P, Klotsas AE, et al. Procedural confidence in hospital based practitioners: implications for the training and practice of doctors at all grades. BMC Med Educ 2009;9:2.

27 Whittle SR, Eaton DG, Murdoch Eaton DG. Attitudes towards transferable skills in medical undergraduates. Med Educ 2001;35:148-53.

28 Theobald J, Gaglani S, Haynes MR. The association between confidence and accuracy among users of a mobile web platform for medical education. Ann Intern Med 2015;162:395-6.

29 Blanch DC, Hall JA, Roter DL, et al. Medical student gender and issues of confidence. Patient Educ Couns 2008;72:374-81

30 Dayal A, O'Connor DM, Qadri U, et al. Comparison of male vs female resident milestone evaluations by faculty during emergency medicine residency training. JAMA Intern Med 2017;177:651-7.

31 Mueller AS, Jenkins TM, Osborne M, et al. Gender differences in attending physicians' feedback to residents: a qualitative analysis. J Grad Med Educ 2017;9:577-85

32 Kolehmainen C, Brennan M, Filut A. Afraid of being "witchy with a ' $b^{\prime \prime \prime}$ : a qualitative study of how gender influences residents' experiences leading cardiopulmonary resuscitation. Acad Med 2014:89:276-1281.

33 Banaji MR, Bhaskar R, Brownstein M. When bias is implicit, how might we think about repairing harm? Curr Opin Psychol 2015;6:183-8.

34 Project implicit: Harvard University. 2011. Available: https://implicit.harvard.edu/implicit/ [Accessed 19 May 2018].

35 Files JA, Mayer AP, Ko MG, et al. SPEAKER introductions at internal medicine grand rounds: Forms of address reveal gender bias. J Womens Health 2017:26:413-9.

36 Meyerson SL, Sternbach JM, Zwischenberger JB, et al. The effect of gender on resident autonomy in the operating room. J Surg Educ 2017;74:e111-8. 
37 Nebeker CA, Basson MD, Haan PS, et al. Do female surgeons learn or teach differently? Am J Surg 2017;213:282-7.

38 Sidhu NS, Edwards M. Deliberate teaching tools for clinical teaching encounters: a critical scoping review and thematic analysis to establish definitional clarity. Med Teach 2018:1-15.

39 Accreditation Council for Graduate Medical Education. ACGME data resource book, academic year 2016-2017. Chicago. 2017. Available: http:// www.acgme.org/About-Us/Publications-andResources/Graduate-Medical-Education-DataResource-Book [Accessed 3 Aug 2018].

40 Khan J, Gilbert J, Sharma A, et al. Perspectives of anesthesia residents training in Canada on fellowship training, research, and future practice location. Can J Anesth/J Can Anesth 2015:62:956-63.
41 Devine PG, Forscher PS, Austin AJ, et al. Longterm reduction in implicit race bias: a prejudice habit-breaking intervention. J Exp Soc Psychol 2012:48:1267-78.

42 Burns MD, Monteith MJ, Parker LR. Training away bias: the differential effects of counterstereotype training and self-regulation on stereotype activation and application. J Exp Soc Psychol 2017;73:97-110 